\title{
The cerebellum is a common site of affection in Leigh syndrome
}

\author{
Josef Finsterer $^{1} \cdot$ Sinda Zarrouk-Mahjoub ${ }^{2}$
}

Received: 30 July 2017 / Accepted: 20 September 2017 / Published online: 30 September 2017

(C) Springer Science+Business Media, LLC 2017

Letter to the Editor.

We read with interest the article by Kilic et al. about a 4 months old male with dysmorphism, hypotonia, developmental delay, tetraspasticity, respiratory insufficiency, impaired hearing, and bilateral inguinal hernia (Kılıç et al. 2017). Cerebral imaging revealed Leigh-like lesions, volume loss of the thalami, and white matter lesions (K1liç et al. 2017). We have the following comments and concerns.

The patient had a double trouble (K1liç et al. 2017). A chromosomal defect and a nuclear mutation. Which of these two variants was responsible for the phenotype? Dysmorphism, hypotonia, developmental delay, tetraspasticity, respiratory insufficiency, impaired hearing, and bilateral inguinal hernia have been also reported in patients with Down syndrome (Picciotti et al. 2017). How can the authors be sure that these presentations were the phenotypic manifestations of the MRPS22 variant?

The MRPS22 variant was found in the homozygous form in the index case (K1lıc et al. 2017). Were the two parents also tested for the mutation? Since they were consanguineous it is quite likely that they carried the mutation each in the heterozygous form. Did either of the parents manifest

Both authors contributed equally.

Josef Finsterer

fifigs1@yahoo.de

Krankenanstalt Rudolfstiftung, Postfach 20, 1180 Vienna, Austria

2 University of Tunis El Manar and Genomics Platform, Pasteur Institute of Tunis, Tunis, Tunisia clinically? Were other siblings clinically affected? Were other siblings tested for the mutation?

The patient had progressive quadruparesis and tetraspasticity (Kılıç et al. 2017). Was weakness solely attributable to the cerebral lesions or did the index case also develop myopathy? Was the patient ever investigated for muscle involvement? Did the cerebral lesions progress with deterioration of the phenotype?

Cerebral lesions in patients with Leigh syndrome may go along with epilepsy (Hallmann et al. 2016; Tarnopolsky et al. 2013). Particularly myoclonic epilepsy has been reported in Leigh patients (Tarnopolsky et al. 2013). Did the index case ever develop seizures and did EEG recordings show paroxysmal activity? Was the family history positive for epilepsy? Did any of the first-degree relatives receive antiepileptic drugs?

Patients with Leigh syndrome frequently manifest with lactic acidosis of the cerebrum (Jurkiewicz et al. 2011). Did the index case undergo lumbar puncture and which were the results? Was MR-spectroscopy carried out to see if lactate was elevated in the central nervous system or not? Seizures have been also reported in the case reported by Smits et al.

The patient was followed-up for four years and the disease course was obviously progressive, particularly in the cerebrum (Kılıç et al. 2017). Was the patient also investigated for progression of involvement in organs other than the cerebrum, such as the eyes, ears, heart, lungs, endocrine organs, intestines, kidneys, blood, or skin?

Overall, this interesting case could be more meaningful if more clinical data and more data about the parents and other first-degree relatives would have been provided. It is essential that the phenotype of the chromosomal defect is clearly delineated from the phenotype of the MRPS22 variant. 
Funding No funding was received.

Author contribution JF: design, literature search, discussion, first draft, SZ-M: literature search, discussion, critical comments.

\section{Compliance with ethical standards}

Conflict of interest There are no conflicts of interest.

\section{References}

Kılıç M, Oğuz KK, Kılıç E, Yüksel D, Demirci H, Sağıroğlu MȘ, YücelY1lmaz D, Özgül RK (2017) A patient with mitochondrial disorder due to a novel mutation in MRPS22. Metab Brain Dis. https://doi. org/10.1007/s11011-017-0074-5
Picciotti PM, Carfî A, Anzivino R, Paludetti G, Conti G, Brandi V, Bernabei R, Onder G (2017) Audiologic Assessment in Adults With Down Syndrome. Am J Intellect Dev Disabil 122:333-341

Hallmann K, Kudin AP, Zsurka G, Kornblum C, Reimann J, Stüve B, Waltz S, Hattingen E, Thiele H, Nürnberg P, Rüb C, Voos W, Kopatz J, Neumann H, Kunz WS (2016) Loss of the smallest subunit of cytochrome c oxidase, COX8A, causes Leigh-like syndrome and epilepsy. Brain 139:338-345

Tarnopolsky M, Meaney B, Robinson B, Sheldon K, Boles RG (2013) Severe infantile leigh syndrome associated with a rare mitochondrial ND6 mutation, m.14487T>C. Am J Med Genet A 161A:2020-2023 Jurkiewicz E, Chełstowska S, Pakuła-Kościesza I, Malczyk K, Nowak K, Bekiesińska-Figatowska M, Sykut-Cegielska J, PiekutowskaAbramczuk D, Pronicka E (2011) Proton MR Spectroscopy in Patients with Leigh Syndrome. Neuroradiol J 24:424-428 